OPEN ACCESS

Edited by:

Antonio Valero,

University of Córdoba, Spain

Reviewed by: Yu Ding,

Jinan University, China

Adrian Canizalez-Roman,

Autonomous University of Sinaloa,

Mexico

${ }^{*}$ Correspondence:

Etinosa O. Igbinosa

eigbinosa@gmail.com;

Etinosa.lgbinosa@uniben.edu

${ }^{\dagger}$ These authors have contributed equally to this work

Specialty section: This article was submitted to

Food Microbiology,

a section of the journal

Frontiers in Microbiology

Received: 22 November 2020 Accepted: 17 May 2021

Published: 08 June 2021

Citation:

Igbinosa EO, Beshiru A, Igbinosa IH, Ogofure AG and

Uwhuba KE (2021) Prevalence and Characterization of Food-Borne Vibrio parahaemolyticus From African

Salad in Southern Nigeria.

Front. Microbiol. 12:632266.

doi: 10.3389/fmicb.2021.632266

\section{Prevalence and Characterization of Food-Borne Vibrio parahaemolyticus From African Salad in Southern Nigeria}

\author{
Etinosa O. Igbinosa ${ }^{1 *}$, Abeni Beshiru ${ }^{1,2+}$, Isoken H. Igbinosa', Abraham G. Ogofure ${ }^{1}$ and \\ Kate E. Uwhuba ${ }^{1,2}$ \\ ${ }^{1}$ Applied Microbial Processes and Environmental Health Research Group, Faculty of Life Sciences, University of Benin, \\ Benin City, Nigeria, ${ }^{2}$ Department of Microbiology, College of Natural and Applied Sciences, Western Delta University, \\ Oghara, Nigeria
}

The demand for minimally processed vegetables (African salad) has increased partly due to its inclusion in ready-to-eat foods. Nevertheless, the associated risk of the presence of emergent foodborne pathogens, such as Vibrio parahaemolyticus might be underestimated. The present study was designed to isolate and characterize foodborne $V$. parahaemolyticus from minimally processed vegetables using culturebased methods and molecular approach. A total of 300 samples were examined from retail outlets between November 2018 and August 2019 from Southern Nigeria. The prevalence of vibrios from the overall samples based on the colonial proliferation of yellow, blue-green and/or green colonies on thiosulfate citrate bile salts sucrose agar was $74 / 300$ (24.6\%). An average of two green or blue-green colonies from respective plates was screened for $V$. parahaemolyticus using analytical profile index (API) $20 \mathrm{NE}$. Polymerase chain reaction further confirmed the identity of positive $V$. parahaemolyticus. The counts of $V$. parahaemolyticus ranged from 1.5 to 1,000 MPN/g. A total of 63 recovered $V$. parahaemolyticus were characterized further. The resistance profile of the isolates include ampicillin 57/63 (90.5\%), cefotaxime 41/63 (65.1\%), ceftazidime 30/63 (47.6\%), amikacin 32/63 (50.8\%), kanamycin 15/63 (23.8\%), and oxytetracycline 16/63 (25.4\%). The multiple antibiotic index ranged from 0-0.81. The formation of biofilm by the isolates revealed the following: strong formation 15/63 (23.8\%), moderate formation 31/63 (49.2\%), weak formation 12/63 (19.1\%), and no formation 5/63 (7.9\%). A total of $63 / 63$ (100\%), 9/63 (14.3\%), and 20/63 (31.8\%) of the isolates harbored the tox $R$ gene, TDH-related hemolysin (trh) and thermostable direct hemolysin (tdh) determinants respectively. The isolates with $\mathrm{O} 2$ serogroup were most prevalent via PCR. Isolates that were resistant to tetracycline, kanamycin, and chloramphenicol possessed resistant genes. The presence of multidrug-resistant vibrios in the minimally processed vegetables constitutes a public health risk and thus necessitates continued surveillance.

Keywords: African salad, vibrios, vegetables, food safety, retail outlets, epidemiology 


\section{INTRODUCTION}

Vibrio parahaemolyticus is a Gram-negative halophilic bacterium distributed in estuarine and marine environments ( $\mathrm{Wu}$ et al., 2014). Significant proportions of $V$. parahaemolyticus strains recovered from environmental sources are commensals of marine microbiota, with a few fractions of disease-causing $V$. parahaemolyticus strains. These bacterial infections are commonly connected with food-borne gastroenteritis (Lopatek et al., 2018). The virulent strains of $V$. parahaemolyticus are differentiated from the non-virulent strains by their capability to possess and express toxigenic genes such as, tdhrelated (trh) hemolysin and/or thermostable direct hemolysin (tdh) genes (Letchumanan et al., 2014). The trh and $t d h$ determinants are referred to as important virulence elements of V. parahaemolyticus (Xu et al., 2014). V. parahaemolyticus is often isolated from food with most of the isolates not harboring or expressing pathogenic potentials and hence, less detrimental to humans (Velazquez-Roman et al., 2012). It has been reported by Gutierrez-West et al. (2013) that V. parahaemolyticus isolated from environmental samples don't usually cause diseases in marine animals and humans.

Different approaches for the detection and/or isolation of $V$. parahaemolyticus have been reported. However, the standard procedure for the isolation of $V$. parahaemolyticus employs the use of enrichment media such as alkaline peptone water and selective media such as thiosulfate-citratebile salts-sucrose agar, along with some biochemical tests (Vincent et al., 2015). These methods are essential for the quantification of $V$. parahaemolyticus density in a sample. This aids potential risk estimation for the occurrence of pathogenic strains (Malcolm et al., 2015). Rapid and accurate $V$. parahaemolyticus identification combines both molecular and conventional approaches. V. parahaemolyticus pathogens from food samples are detected using polymerase chain reaction methods which amplifies the toxin operon gene (tox-R) sequences (Law et al., 2015).

Genes responsible for antibiotic resistance (AR) in vibrios are localized in plasmids or chromosomes. Extra-chromosomal genetic materials are crucial mediators responsible for the spread of antibiotic-resistant genes (ARGs) and can be interchanged with other bacteria via horizontal and vertical gene transfer (Manjusha and Sarita, 2011). Biofilms are architecturally complex assemblies of microorganisms on or in biotic or abiotic surfaces and interfaces, characterized by interactions between the populations. Biofilms contain exopolymeric substances and survive as self-organized, three-dimensional structures that exhibit altered phenotypic and genotypic characters (Mizan et al., 2015). V. parahaemolyticus is known to form biofilms on food and food contact surfaces. Like other biofilm-producing microorganisms, V. parahaemolyticus is capable of producing distinct types of adherence factors that enable the bacterium to adhere to the surface and initiate biofilm formation (Donlan, 2002). Bacterial biofilm potentials can support resistance to some physical and/or chemical agents thereby improving their resistance profile (Beshiru and Igbinosa, 2018). Formation and development of biofilm is complex and heterogeneous which makes phenotypic readouts acceptable as standards for evaluating the impacts of biofilm formation on antibiotics.

African salad contains lots of raw and fresh vegetables attached to some other ingredients that are eaten without further processing, which makes it a salad of African origin. African salad is generally sourced for due to its constituents. It is known to be rich in carbohydrate, protein, minerals, and vitamins. African salad is often consumed as a meal or as an alternate dish to the numerous Nigerian food recipes (Maky, 2013). Although Nigeria has no official foodborne disease surveillance system, foodborne infection is endemic in Nigeria and its direct cost is estimated at $\$ 3$ billion, accounting for $17-25 \%$ of the estimated cost of all illnesses (Oludare et al., 2016). The local government health system profile in Nigeria revealed food-borne illnesses as the leading cause of death, accounting for $25 \%$ mortality. An outbreak of food poisoning in Ibadan, Nigeria, claimed about 20 lives (Osagbemi et al., 2010). Cases of food poisoning among families in Kano and Ilorin Nigeria due to consumption of yam flour have been documented (Adedoyin et al., 2008; Adeleke, 2009). An acute onset of gastrointestinal symptoms among people who had attended and eaten at a burial ceremony resulted in 60 case patients and three deaths (Fatiregun et al., 2010). The World Health Organization (WHO) estimates that $>200,000$ people die of food poisoning annually in Nigeria from foodborne pathogens. The deaths were caused by contaminated foods through improper processing, preservation and service World Health Organization [WHO], 2009.

In Nigeria, a large proportion of ready-to-eat foods are sold by the informal sector, especially as street foods. The hygienic aspects of vending operations and the safety of these foods are problematic for food safety regulators. The global food crisis has worsened an already precarious food situation because when food is in short supply and/or expensive, people are more concerned about satisfying hunger than the safety of the food. It has been revealed that in Nigeria, $27.7 \%$ of food handlers do not wash their hands before preparing food and $28.1 \%$ use only water to wash hands after using the toilet. The knowledge of food handlers about the food borne infections (FBIs) and their safety practices is an important issue in the outbreaks of FBI. It was also revealed that $90 \%$ of food handlers have heard about foodborne infection out of which only $15.6 \%$ of them know how it is contracted (Smith et al., 2010). Furthermore, large quantity of food produced and distributed gets to the consumers in an unwholesome condition due to poor handling methods, inefficient processing equipment and storage practices, high ambient tropical temperature and humidity conditions (Akintaro, 2012).

Vibrio parahaemolyticus have been recovered from seafoods in different parts of Nigeria (Adebayo-Tayo et al., 2011; Oramadike and Ogunbanwo, 2015; Beshiru et al., 2020). Other bacteria (such as $P$. aeruginosa, $P$. putida, P. mendocina, E. coli, Staphylococcus spp., Pseudomonas spp., C. septicum, Micrococcus spp., and B. alvei, Enterococcus spp., K. pneumoniae, Salmonella spp., Shigella spp., Citrobacter spp., B. thuringiensis, B. subtilis, and $B$. licheniformis) have been recovered from other ready-toeat foods in Nigeria which includes Buns, Meat pie, Egg roll, Wara, Kununzaki, Suya, Rice, Beans, Bread, Akara, Potato, and Yam (Bukar et al., 2009; Adio et al., 2014; Agwa et al., 2014; 
Madueke et al., 2014; Aruwa and Ogunlade, 2016; Fadahunsi and Makinde, 2018; Obande et al., 2018; Igbinosa et al., 2020; Beshiru et al., 2021). Oguwike et al. (2014) detected Salmonella spp., Shigella spp., and S. aures from African salads in Enugu Nigeria. The predominant bacterial isolates from African salad by Oranusi et al. (2013b) in Owerri Imo State Nigeria belong to Bacillus spp., Staphylococcus spp., Escherichia coli, Enterococci and Serracia spp. The species of bacteria isolated by Daniel et al. (2016) from African salads in Benin City Edo State were identified as Listeria sp., E. coli, Klebsiella sp., Proteus sp., Salmonella sp., Staphylococcus aureus, and Shigella sp. Furthermore, Proteus vulgaris, S. aureus, Citrobacter freundii, Proteus mirabilis, and Corynebacterium spp. were recovered from pre-packed mixed vegetable salad within Lagos metropolis Nigeria (Uzeh et al., 2009). Acinetobacter baumannii, Bacillus sp., Enterobacter sp., E. coli, Klebsiella sp., Kurthia gibsonii, and Salmonella sp. were recovered from commonly vended African Salads in Owerri Imo State Nigeria (Dike et al., 2017). Due to lack of information concerning the detection and characterization of $V$. parahaemolyticus from African salads sold in retail outlets despite their increased consumption, we aimed to investigate $V$. parahaemolyticus from African salads.

Gastroenteritis outbreaks which result from $V$. parahaemolyticus have been reported globally, such as in Japan (Arakawa et al., 1999), Europe (Lopatek et al., 2018), South America (Raszl et al., 2016), and United States (Shaw et al., 2014). Due to the poor repository and documentation from food outbreaks in Nigeria, it is difficult to show statistics of $V$. parahaemolyticus outbreaks. However, to date, there is limited literature on the contamination levels, prevalence, and pathogenic profiles of $V$. parahaemolyticus from African salads. Hence, we presented information indicating the importance of coordinated detection and characterization of $V$. parahaemolyticus strains from African salads.

\section{MATERIALS AND METHODS}

\section{Sample Collection}

The study focused on African salads from eight States in southern Nigeria (Edo State, Delta State, Imo State, Anambra State, Enugu State, Abia State, Ondo State, and Lagos State). Sample size determination formula was used in this study to determine the sample size as follows:

$$
\text { Sample }(\mathrm{N})=\frac{\left(\mathrm{Z}_{1-\alpha / 2}\right)^{2} \mathrm{P}(1-\mathrm{P})}{\mathrm{d}^{2}}
$$

$Z_{1-\alpha / 2}=$ Standard normal variant at $5 \%$ type I error $(P<0.05)$; $\mathrm{P}=$ Expected prevalence based on previous study $[20.65 \%$ from Tunung et al. (2010); 8.4\% from Kriem et al. (2015); 15\% from Obaidat et al. (2017) were used]; $d=$ Absolute error or precision (which is 5\%). Hence, the expected sample size was a minimum of 118 samples. A total of 300 African salad samples were thereafter randomly purchased from retails outlets from respective eight (08) states covering the southern region of Nigeria between November 2018 and August 2019. All the samples were sealed and conveyed in an icebox to the Applied Microbial Processes and Environmental Health Research (AMPEHREG) laboratory for analysis within $12 \mathrm{~h}$ of sample collection.

\section{Enumeration and Isolation of Vibrio parahaemolyticus From the African Salad Samples}

Twenty-five (25) grams of African salad samples were weighed and immersed into a sterile homogenizer bag which contains $225 \mathrm{~mL}$ of alkaline peptone water (Lab M, Lancashire, United Kingdom), $\mathrm{pH} 8.5,2 \% \mathrm{NaCl}$, giving a first-order dilution $\left(10^{-1}\right)$. The samples were homogenized for $1 \mathrm{~min}$ at $800 \mathrm{rpm}$ using a shaker. A $3 \times 10 \mathrm{~mL}$ portion of the 1:10 dilution which represents the $1 \mathrm{~g}$ portion was inoculated into three tubes containing $10 \mathrm{~mL}$ of $2 \times$ alkaline peptone water. Similarly, $3 \times 1 \mathrm{~mL}$ portions of the 1:10, 1:100, and 1:1,000 dilutions were inoculated into $10 \mathrm{~mL}$ of single-strength alkaline peptone water and incubated overnight at $35 \pm 2{ }^{\circ} \mathrm{C}$. Streak plate technique using a $3-\mathrm{mm}$ loopful from the top $1 \mathrm{~cm}$ of the alkaline peptone water tubes containing the highest dilutions of the sample showing growth was inoculated onto thiosulphate-citrate-bile salt-sucrose (TCBS) agar (Lab M, Lancashire, United Kingdom) and incubated at $35 \pm 2{ }^{\circ} \mathrm{C}$ overnight. $V$. parahaemolyticus appear as $2-3 \mathrm{~mm}$ in diameter, opaque, round, bluish-green or green colonies, on TCBS agar. A minimum of two and maximum of five colonies were selected for identification. The biochemical and morphological test employed includes: urease test using Christensen's urea agar (Lab M, Lancashire, United Kingdom) supplemented with $2 \% \mathrm{NaCl}$, $3 \% \mathrm{KOH}$, arginine glucose slant test, motility test, oxidase test, $3.5 \% \mathrm{NaCl}$ triple-sugar-iron, Gram staining, ortho-Nitrophenyl$\beta$-galactoside (ONPG) test, sugar fermentation test (lactose and cellobiose reactions), $\mathrm{T}_{1} \mathrm{~N}_{0}$ and $\mathrm{T}_{1} \mathrm{~N}_{3}$ broths (QingDao HopebioTechnology, China) test and salt tolerance test. Cell suspensions of tentative $V$. parahaemolyticus in $2 \% \mathrm{NaCl}$ were further screened using analytical profile index (API) 20NE. The tests were performed according to the manufacturer's instruction for use. Data interpretation was carried out using the API database (V4.1) with the apiweb ${ }^{\mathrm{TM}}$ identification software. Confirmed isolates were purified on tryptone soy agar (Lab M, Lancashire, United Kingdom) supplemented with $2 \% \mathrm{NaCl}$ and stored in nutrient agar (Lab M, Lancashire, United Kingdom) slants containing $2 \% \mathrm{NaCl}$ at $4^{\circ} \mathrm{C}$. V. parahaemolyticus colonies were expressed in $\mathrm{MPN} / \mathrm{g}$.

\section{Identification of Vibrio parahaemolyticus and Detection of Virulence Genes}

Pure isolates where DNA was extracted were resuscitated on tryptone soy broth (Lab M, Lancashire, United Kingdom) and incubated for $18 \mathrm{~h}$ at $37^{\circ} \mathrm{C}$. DNA isolation was carried out using PeqGold Bacterial DNA kit (Peqlab Biotechnologie $\mathrm{GmbH}$, Germany) following the manufacturers' instruction. PCR amplification for detection of tox-R, trh and $t d h$ elements was carried out via PCR using specific primers and annealing conditions stated in Supplementary Table 1 below. This was conducted using a final volume of $20 \mu \mathrm{L}$, containing $10 \mu \mathrm{L}$ of 
$2 \times$ Taq polymerase, MasterMix, $2 \mu \mathrm{L}$ of DNA template, $1 \mu \mathrm{L}$ each primer concentration of $05 \mu \mathrm{M}$, and $6 \mu \mathrm{L}$ of sterile distilled water. The PCR amplifications were performed using a PeltierBased Thermal Cycler (BioSeparation System, China) with the following cycling conditions: initial denaturation for $3 \mathrm{~min}$ at $94^{\circ} \mathrm{C}, 30$ cycles for $1 \mathrm{~min}$ at $94^{\circ} \mathrm{C}, 1 \mathrm{~min}$ at $58^{\circ} \mathrm{C}$ and $1 \mathrm{~min}$ at $72^{\circ} \mathrm{C}$, and a final elongation for $5 \mathrm{~min}$ at $72^{\circ} \mathrm{C}$. All PCR products were visualized by using $1.0 \%$ agarose gel (CLS-AG100, United Kingdom) in $0.5 \times$ TAE buffer and allowed to run for $1 \mathrm{~h}$ at $100 \mathrm{~V}$. The gels were visualized using UV transilluminator (EBOX VX5; France). V. parahaemolyticus DSM 11058 was used as a positive control and double-distilled water $\left(\mathrm{ddH}_{2} \mathrm{O}\right)$ as a negative control in every PCR reactions.

\section{Biofilm Formation, Hemolytic Response and Screening for $O$ Serogroups}

Biofilm formation was assayed via the microtiter plate method as described previously by Beshiru et al. (2018). Wagatsuma agar (HiMedia, India) was used to elucidate hemolytic response by adopting the Kanagawa phenomenon. The serogroups of $V$. parahaemolyticus isolates were identified via PCR technique using primer sets and amplification conditions as previously described (Chen et al., 2012). V. parahaemolyticus DSM 11058 was used as a positive control and $\mathrm{ddH}_{2} \mathrm{O}$ as a negative control in all PCR reactions.

\section{Antimicrobial Susceptibility Profile of the Isolates}

Antimicrobial susceptibility profile of the $V$. parahaemolyticus isolates was performed using Kirby-Bauer disk diffusion method and readings interpreted by adopting the breakpoints of Clinical and Laboratory Standard Institute. Briefly, purified isolates were inoculated on $5 \mathrm{~mL}$ Mueller Hinton broth (Lab M, United Kingdom) and incubated overnight. The OD of the broth was determined to be equivalent to $\times 10^{6} \mathrm{CFU} / \mathrm{mL}$. With sterile swab sticks, respective standards were aseptically swabbed on Mueller Hinton agar (Lab M, United Kingdom). Antibiotics employed in this study include the recommended antibiotics by the Centre for Disease Control and Prevention for the treatment of vibrios infections (Shaw et al., 2014). A total of 19 antibiotic disks (Mast Diagnostics, United Kingdom) which includes: ceftazidime $(30 \mu \mathrm{g})$, ampicillin $(10 \mu \mathrm{g})$, imipenem $(10 \mu \mathrm{g})$, cefotaxime $(30 \mu \mathrm{g})$, amikacin $(30 \mu \mathrm{g})$, ampicillin/sulbactam $(10 / 10 \mu \mathrm{g})$, cefazolin $(30 \mu \mathrm{g})$, cephalothin $(30 \mu \mathrm{g})$, gentamicin (10 $\mu \mathrm{g})$, azithromycin (15 $\mu \mathrm{g})$, chloramphenicol $(30 \mu \mathrm{g})$, ciprofloxacin $(5 \mu \mathrm{g})$, levofloxacin $(5 \mu \mathrm{g})$, kanamycin $(30 \mu \mathrm{g})$, streptomycin $(10 \mu \mathrm{g})$, nalidixic acid $(30 \mu \mathrm{g})$, tetracycline $(30 \mu \mathrm{g})$, oxytetracycline $(30 \mu \mathrm{g})$, and trimethoprim-sulfamethoxazole $(1.25 / 23.75 \mu \mathrm{g})$. The respective disks were also impregnated aseptically on the agar plates equidistant apart and incubated at $37^{\circ} \mathrm{C}$ for $18-24 \mathrm{~h}$. Characterization of the resistance (R), intermediate (I) or susceptibility (S) profile of the isolates was determined by measuring inhibitory zones and then compared with the interpretative chart to determine the sensitivity, intermediate and resistant nature of the isolates to the antibiotics used using the interpretative chart by
Clinical and Laboratory Standard Institute [CLSI] (2018).

Multiple antibiotic resistance index (MARI) and multidrug resistance (MDR) were determined as described previously (Igbinosa and Beshiru, 2019).

\section{Screening for Antibiotic Resistance Genes}

Vibrio parahaemolyticus isolates that revealed resistance phenotypes were screened for corresponding resistance elements. The elements associated with resistance to sulfamethoxazole (sul3, sul2, and sul1), kanamycin (aphA-3), chloramphenicols (catA1, catA2, catA3, and catB3), trimethoprim (dfr), tetracyclines (tet $M$, tet $G$, tet $C$, tet $B$, and tet $A)$, and $\beta$-lactams (blaOXA, blaSHV, and blaTEM) were detected by PCR (Kim et al., 2013). ARGs primers are listed below (Supplementary Table 1). The amplification procedure was performed using a Peltier-Based Thermal Cycler (BioSeparation System, Shanxi, China) with the following cycling conditions: initial denaturation at $94^{\circ} \mathrm{C}$ for $3 \mathrm{~min}, 35$ cycles at $94^{\circ} \mathrm{C}$ for $30 \mathrm{~s}, 1 \mathrm{~min}$ at $52^{\circ} \mathrm{C}$ and $90 \mathrm{~s}$ at $72^{\circ} \mathrm{C}$, and final elongation at $72^{\circ} \mathrm{C}$ for $6 \mathrm{~min}$. All PCR products were visualized by using $1.5 \%$ agarose gel (CLS-AG100, United Kingdom) in $0.5 \times$ TAE buffer and run for $1 \mathrm{~h}$ at $100 \mathrm{~V}$. The gels were visualized using UV transilluminator (EBOX VX5; France).

\section{Statistical Analysis}

Data were analyzed using the SPSS statistical software (Version 21.0). Descriptive statistics were used to estimate the mean and standard deviation. Correlation analysis was used to elucidate the impact of one virulence factor/determinant on another. The $p$-values $<0.05$ were considered significant statistically.

\section{RESULTS}

\section{Prevalence and Population Cell Density of Vibrio parahaemolyticus From African Salads}

The prevalence of vibrios from the overall samples based on the colonial occurrence of yellow, green and/or blue-green colonies on TCBS agar was $74 / 300$ (24.6\%). The prevalence of $V$. parahaemolyticus via API $20 \mathrm{NE}$ and PCR was $33 / 300$ (11\%). The cell density of $V$. parahaemolyticus ranged from 1.5 to $1,000 \mathrm{MPN} / \mathrm{g}$ (Figure 1). From the positive samples (samples which harbored $V$. parahaemolyticus), 7/33 (21.21\%) contained bacterial load $<3 \mathrm{MPN} / \mathrm{g}, 13 / 33$ (39.39\%) contained a load 3-10 MPN/g, 9/33 (27.27\%) contained > 10-100 MPN/g, and $4 / 33(12.12 \%)$ samples contained $>100-1,000 \mathrm{MPN} / \mathrm{g}$ (Figure 1). Statistically, a significant difference exists in the $V$. parahaemolyticus density based on samples from different locations (states) $(p<0.05)$. A total of 63 isolates were recovered. The distribution of the $63 \mathrm{~V}$. parahaemolyticus isolates is as follows: Edo State 7/63 (11.11\%), Delta State 10/63 (15.87\%), Imo State 9/63 (14.29\%), Anambra State 8/63 (12.69\%), Enugu State $9 / 63$ (14.29\%), Abia State 7/63 (11.11\%), Lagos State 8/63 (12.69\%), and Ondo State 5/63 (7.94\%). 


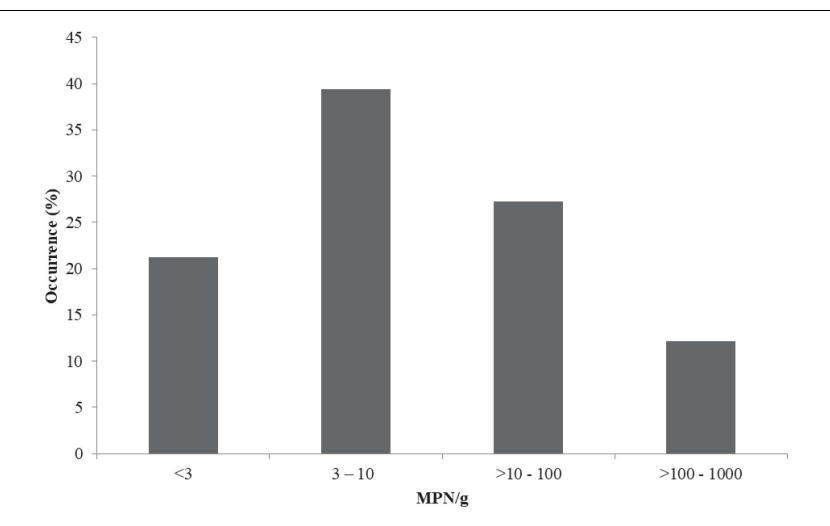

FIGURE 1 | Levels of $V$. parahaemolyticus in African salads. MPN/g, most probable number per gram; <, less than; > , greater than.

\section{Prevalence of Phenotypic and Genotypic Virulence Profile of Vibrio parahaemolyticus From African Salads}

The prevalence in Figure 2 include: Urease $+2 \% \mathrm{NaCl} 20 / 63$ $(21.75 \%)$ and hemolytic response $9 / 63$ (14.29\%). A total of $63 / 63$ (100\%), $9 / 63(14.3 \%)$, and $20 / 63(31.8 \%)$ of the isolates harbored the tox $R, t d h$, and trh genes, respectively (Figure 2). Urease $+2 \% \mathrm{NaCl}$ significantly correlated hemolytic response $(r=0.599, p<0.01)$, tdh genes $(r=1.000, p<0.01)$ and $t r h$ genes $(r=0.599, p<0.01)$ as shown in Supplementary Table 3. In addition, $t d h$ genes significantly correlated $t r h$ genes $(r=0.599$, $p<0.01)$. The biofilm formation profile in Figure 3 revealed the following: strong formation 15/63 (23.8\%), moderate formation $31 / 63$ (49.2\%), weak formation $12 / 63$ (19.1\%), and no formation

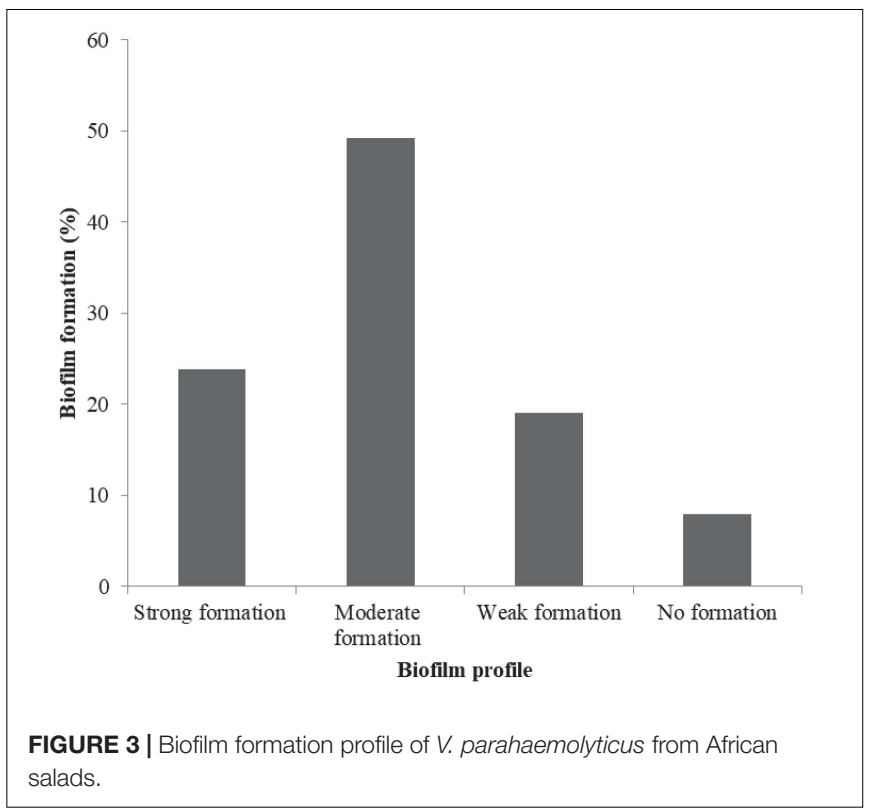

5/63 (7.9\%). Overall, 58/63 (92.1\%) of the isolates formed biofilm. Biofilm formation significantly correlated Urease $+2 \% \mathrm{NaCl}$ $(r=0.686, p<0.01)$, hemolytic response $(r=0.424, p<0.01), t d h$ genes $(r=0.424, p<0.01)$, and $t r h$ genes $(r=0.686, p<0.01)$. The prevalence of the serogroups in Figure 4 is as follows: $\mathrm{O} 17 / 63$ (11.11\%), O2 22/63 (34.92\%), O4 2/63 (3.17\%), O6 3/63 (4.76\%), O7 1/63 (1.59\%), O10 4/63 (6.35\%), O11 2/63 (3.18\%), O12 16/63 (25.39\%), and uncertain 6/63 (9.52\%). Location and serogroups had no correlation on the phenotypic and/or genotypic profile of the isolates (Supplementary Table 3).

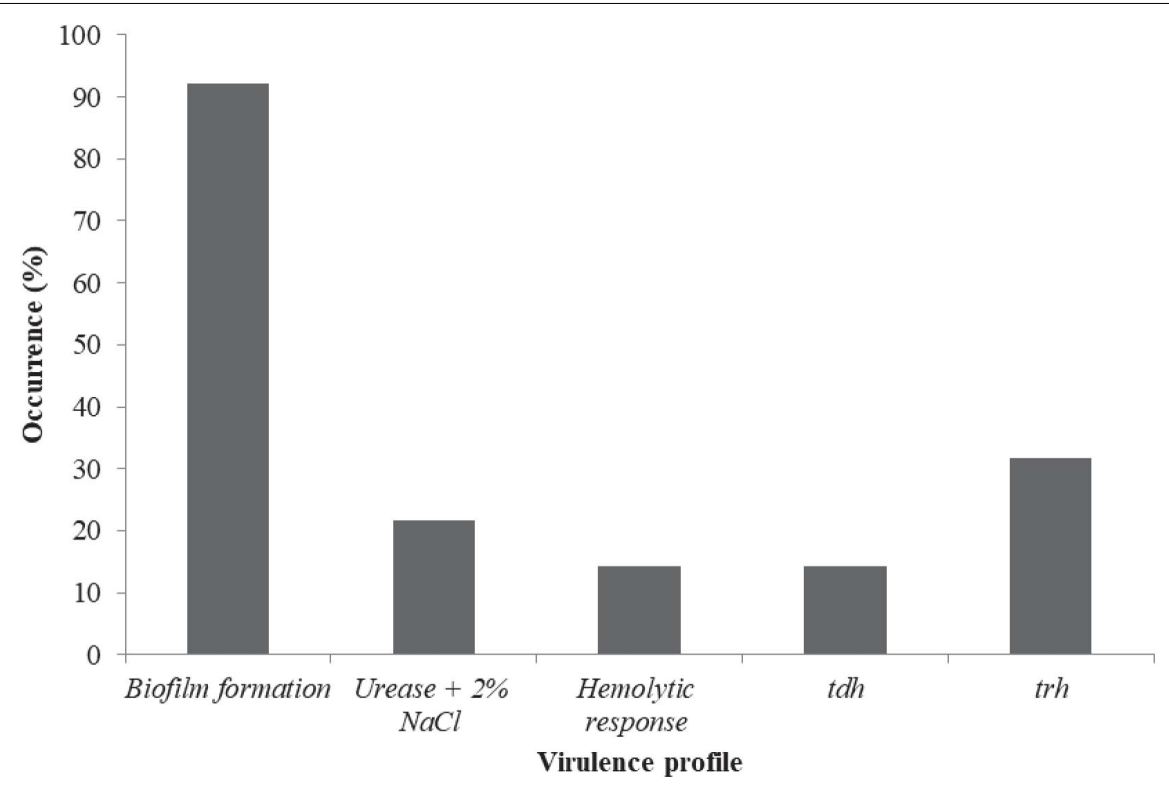

FIGURE 2 | Phenotypic and genotypic virulence profile of $V$. parahaemolyticus from African salads. Thermostable direct hemolysin (tdh) and TDH-related hemolysin (trh). 


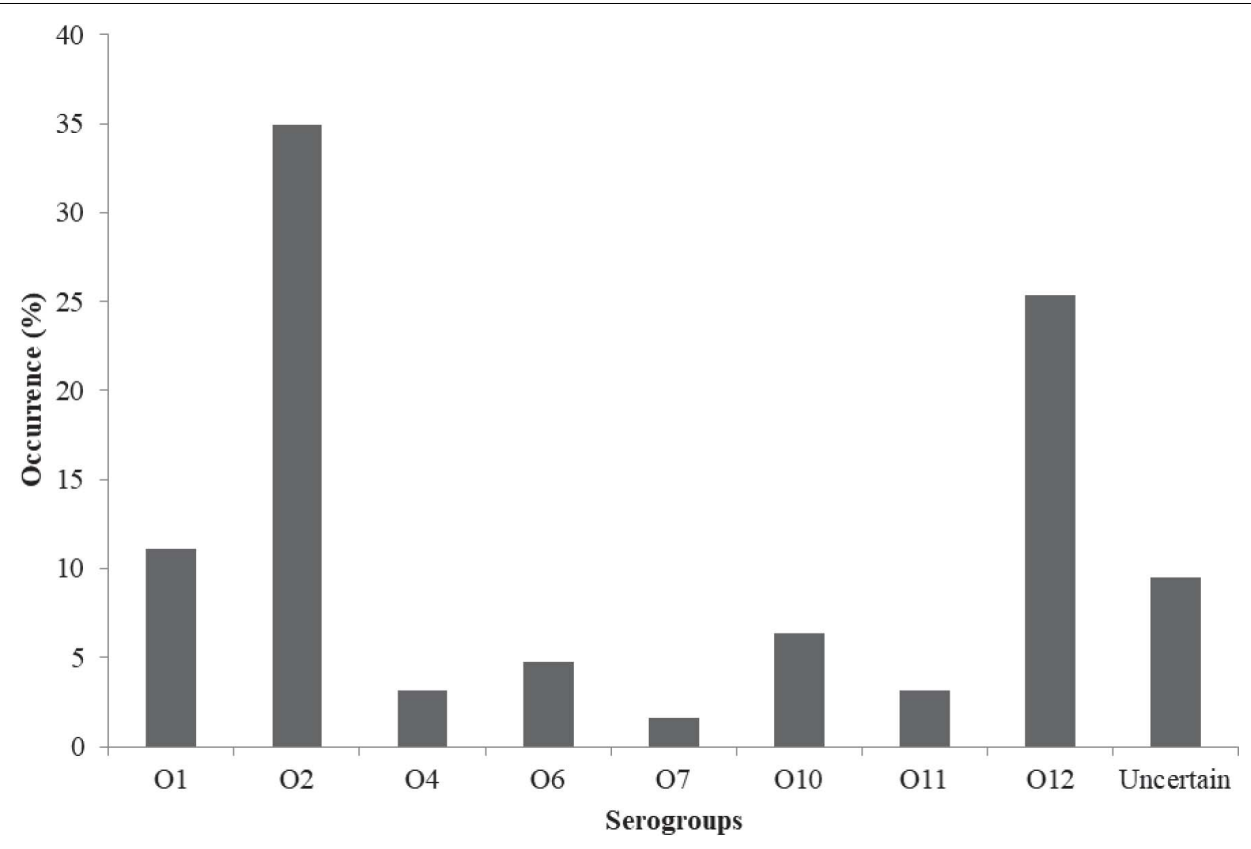

FIGURE 4 | Distribution of serogroups of $V$. parahaemolyticus from African salads.

\section{Antimicrobial Susceptibility Profile of Vibrio parahaemolyticus Isolates From African Salads}

Antimicrobial susceptibility profile of $V$. parahaemolyticus from African salads in Table $\mathbf{1}$ is as follows: ampicillin 57/63 (90.5\%), cefotaxime 41/63 (65.1\%), cephalothin 37/63 (58.7\%), amikacin 32/63 (50.8\%), ceftazidime 30/63 (47.6\%), cefazolin $29 / 63(46.0 \%)$, streptomycin 19/63 (30.2\%), oxytetracycline $16 / 63(25.4 \%)$, kanamycin 15/63 (23.8\%), ciprofloxacin 10/63 (15.9\%), tetracycline $12 / 63(19.1 \%)$, and trimethoprimsulfamethoxazole 10/63 (15.9\%). High level of sensitivity observed includes nalidixic acid 62/63 (98.4\%), imipenem 54/63 (85.7\%), ciprofloxacin 49/63 (77.8\%), azithromycin 49/63 (77.8\%), levofloxacin 48/63 (76.2\%), gentamicin 46/63 (73.0\%), tetracycline $43 / 63(68.3 \%)$, and trimethoprim-sulfamethoxazole 35/63 (55.6\%). The MDR profile in Figure 5 revealed that 39/63 (61.9\%) of the isolates had MDR potential (resistant to $\geq 3$ antibiotics in $\geq 3$ antimicrobial class). The MAR index ranged from $0.05-0.68$ (Figure 6) with $35 / 63(53.8 \%$ ) of the isolates having MAR index $>0.2$. A total of $4 / 63(6.3 \%)$ isolates were not resistant to any of the antibiotics used with MAR index of 0.00 while $18 / 63$ (28.6\%) of the $V$. parahaemolyticus were resistant to one antibiotic with MAR index of 0.05 . A total of $3 / 63(4.8 \%)$ of the $V$. parahaemolyticus were resistant to three antibiotics with MAR index of 0.16 . The MAR index significantly correlates the formation of biofilm $(r=0.474, p<0.01)$.

\section{Antibiotic Resistance Genes in the Vibrio parahaemolyticus}

Vibrio parahaemolyticus isolates that were resistant to kanamycin ( $n=15)$, chloramphenicol $(n=14)$, tetracycline $(n=12)$, trimethoprim-sulfamethoxazole $(n=10)$ and $\beta$-lactam $(n=57)$, were screened for the occurrence of their respective resistance genes [kanamycin (aphA-3), chloramphenicol (catA2, catA1, cat $B 3$, and cat $A 3)$, tetracycline (tet $A, \operatorname{tet} B$, tet $C$, tet $G$, and tet $M)$, trimethoprim ( $d f r)$, sulfamethoxazole (sul3, sul2, and sull), and $\beta$-lactam (blaTEM, blaOXA and blaSHV)]. Resistance genes such as sul3 1/10 (10\%), sul2 5/10 (50\%), and sul1 5/10 (50\%) were detected from the sulfamethoxazole resistance (Figure 7). In addition, 5/15 (33.3\%) of aphA-3 and 4/10 (40\%) of $d f r$ of $V$. parahaemolyticus isolates were detected. Others include catA2 14/14 (100\%), catB3 3/14 (21.4\%), tetM 10/12 (83.3\%), and blaTEM 6/57 (10.5\%). catA1, cat $A 3$, tet $A$, tet $B$, tet $C$, tet $G$, blaOXA, and blaSHV were not detected (Figure 7).

\section{DISCUSSION}

The occurrence of disease-causing $V$. parahaemolyticus strains in salads is of immense concern to public health as this is a frequent causal organism of food-borne gastroenteritis in humans. The highest microbial density of 3-10 MPN/g (13/33; $39.39 \%$ ) observed in this study is familiar to the study of Yang et al. (2017) and $\mathrm{Xu}$ et al. (2016). However, it was higher compared to the finding of Tunung et al. (2010). The level of $V$. parahaemolyticus prevalence in this study appears to be lower when compared to the findings of Lee et al. (2018) in which $69 \%(165 / 240)$ of the analyzed samples were known to be positive to $V$. parahaemolyticus (based on toxR PCR assay). Similarly, the study of Tan et al. (2017) and Narayanan et al. (2020) showed the prevalence of $V$. parahaemolyticus in samples analyzed as 79.5 and $90 \%$ respectively. Contrarily, the study of Yang et al. (2017) demonstrated a lower level 
$V$. parahaemolyticus prevalence as $19.44 \%$ in tested samples. African salad is a ready-to-eat food therefore the presence of pathogenic $V$. parahaemolyticus ( $>100-1,000 \mathrm{MPN} / \mathrm{g}$ ) in this study is of paramount public health concern.

The detection of $V$. parahaemolyticus in African salad could be as a result of the materials used in the preparation process, notably the vegetable, water, and seafood. The previous report by Eni et al. (2010) has implicated vegetables as a veritable source of microbial pathogens. In further agreement with this study, Eni et al. (2010); Tunung et al. (2010); and Oranusi et al. (2013b) reported the presence of microbial contamination in African salad. Oranusi et al. (2013a) further emphasize the hazard resulting from the consumption of undercooked and moderately cooked food as they are likely to retain more pathogens even though they could contain more nutrients. Increase in FBI has been linked with the lack of knowledge of FBIs and poor food safety practice (FSP) of food handlers. This is a major determinant of the kind of patronage received by fast food and local restaurants. Inadequate food safety laws, weak regulatory systems, lack of financial resources to invest in safer equipment, inadequate knowledge of food borne diseases and their causes, improper handling of food and unhygienic environments among others have been identified as some of the causes of FBI (Haileselassie et al., 2013).

TABLE 1 | Antibiotic susceptibility profile of the $V$. parahaemolyticus isolates.

Antimicrobial Antibiotics $\quad$ V. parahaemolyticus $(n=63)$
class

Resistance Intermediate Sensitive

\begin{tabular}{|c|c|c|c|c|}
\hline \multirow[t]{2}{*}{ Penicillins } & $\begin{array}{l}\text { Ampicillin/sulbactam } \\
(10 / 10 \mu \mathrm{g})\end{array}$ & 18 (28.6) & $12(19.0)$ & $33(52.4)$ \\
\hline & Ampicillin $(10 \mu \mathrm{g})$ & 57 (90.5) & $6(9.5)$ & $0(0)$ \\
\hline \multirow[t]{4}{*}{ Aminoglycosides } & Amikacin (30 $\mu \mathrm{g})$ & $32(50.8)$ & $21(33.3)$ & $10(15.9)$ \\
\hline & Gentamicin $(10 \mu \mathrm{g})$ & $6(9.5)$ & $11(17.5)$ & $46(73.0)$ \\
\hline & Kanamycin $(30 \mu \mathrm{g})$ & $15(23.8)$ & 25 (39.6) & $23(36.5)$ \\
\hline & $\begin{array}{l}\text { Streptomycin } \\
(10 \mu \mathrm{g})\end{array}$ & $19(30.2)$ & $32(50.8)$ & $12(19.1)$ \\
\hline Carbapenems & Imipenem $(10 \mu \mathrm{g})$ & $2(3.2)$ & $7(11.1)$ & $54(85.7)$ \\
\hline \multirow[t]{4}{*}{ Cephalosporins } & Cefotaxime $(30 \mu \mathrm{g})$ & $41(65.1)$ & 9 (14.3) & 13 (20.6) \\
\hline & Ceftazidime $(30 \mu \mathrm{g})$ & $30(47.6)$ & $12(19.1)$ & $21(33.3)$ \\
\hline & Cephalothin $(30 \mu \mathrm{g})$ & $37(58.7)$ & $11(17.5)$ & $15(23.8)$ \\
\hline & Cefazolin $(30 \mu \mathrm{g})$ & $29(46.0)$ & NA & $34(54.0)$ \\
\hline \multirow[t]{3}{*}{ Quinolones } & $\begin{array}{l}\text { Nalidixic acid } \\
(30 \mu \mathrm{g})\end{array}$ & $1(1.6)$ & $0(0)$ & $62(98.4)$ \\
\hline & Levofloxacin $(5 \mu \mathrm{g})$ & $9(14.3)$ & $6(9.5)$ & $48(76.2)$ \\
\hline & Ciprofloxacin $(5 \mu \mathrm{g})$ & $10(15.9)$ & $4(6.3)$ & $49(77.8)$ \\
\hline Phenicols & $\begin{array}{l}\text { Chloramphenicol } \\
(30 \mu \mathrm{g})\end{array}$ & $14(22.2)$ & $23(36.5)$ & $26(41.3)$ \\
\hline $\begin{array}{l}\text { Folate pathway } \\
\text { inhibitor }\end{array}$ & $\begin{array}{l}\text { Trimethoprim- } \\
\text { sulfamethoxazole } \\
(1.25 / 23.75 \mu \mathrm{g})\end{array}$ & $10(15.9)$ & $18(28.6)$ & $35(55.6)$ \\
\hline \multirow[t]{2}{*}{ Tetracyclines } & Tetracycline $(30 \mu \mathrm{g})$ & $12(19.1)$ & $8(12.7)$ & $43(68.3)$ \\
\hline & $\begin{array}{l}\text { Oxytetracycline } \\
(30 \mu \mathrm{g})\end{array}$ & $16(25.4)$ & 25 (39.6) & $22(34.9)$ \\
\hline Macrolides & Azithromycin $(15 \mu \mathrm{g})$ & $9(14.3)$ & $5(7.9)$ & $49(77.8)$ \\
\hline
\end{tabular}

Vibrio parahaemolyticus strains from food samples have been observed to not usually harbor pathogenic genes trh and/or $t d h$ which accounts for virulence traits of such strains in human (Gutierrez-West et al., 2013). Similarly, it is of note that $V$. parahaemolyticus recovered from the food and environment contains much less pathogenic strains than clinical isolates (Rahimi et al., 2010). Previous studies equally reported that only $1-2 \%$ of the environmental $V$. parahaemolyticus strains usually carry the $t d h$ and/or $t r h$ genes (Velazquez-Roman et al., 2012; Haley et al., 2014). Xu et al. (2014) considered these two genes as the principal virulence elements of $V$. parahaemolyticus. However, some clinical $V$. parahaemolyticus isolates have also been stated not to possess pathogenic characteristics (Xu et al., 2016). Hence where these two hemolysins ( $t d h$ and $t r h$ ) are absent, $V$. parahaemolyticus can remain pathogenic, portraying the existence of other virulence determinants/factors. Hence, the need to investigate other $V$. parahaemolyticus virulence factors such as urease activity, $\beta$-hemolytic activity and biofilm formation. With the urease enzyme, urea is hydrolyzed into carbon dioxide and ammonia, raising the $\mathrm{pH}$ in the immediate environment inside the host or habitat. This microhabitat activity contributes to survival in the digestive tract, inflammation, blood vessel permeability and tissue invasion (Berutti et al., 2014).

Early studies showed that urease induces the accumulation of intestinal fluid in the rabbit ileal loops test and causes gastrointestinal inflammatory lesions, confirming that urease is an important virulence factor in trh positive $V$. parahaemolyticus strains (Cal and Ni, 1996; Osawa et al., 1996; Wang et al., 2015). Findings from our study agree with a previous report by Lopatek et al. (2018) that trh-positive V. parahaemolyticus had urease production potential. This is also similar to the report of Quadri et al. (2005) that trh-positive $V$. parahaemolyticus strains almost always correlate with urease production. In our study, production of urease correlated with the occurrence of trh and $t d h$ genes. Sujeewa et al. (2009) reported that not all urease positive strains of $V$. parahaemolyticus were positive for either $t d h$ or trh determinants. However, Sujeewa et al. (2009) revealed that $t d h$ positive isolates significantly correlated with isolates exhibiting hemolysis, thereby implicating hemolytic activity as a strong indicator for $t d h$ genes. This tallies with the results of this study whereby all isolates that exhibited hemolysis completely correlated with the presence of $t d h$ genes. Though urease production and hemolytic response could be considered as a notable marker of trh and $t d h$ in $V$. parahaemolyticus, they are not accurate as a pathogenic biomarker. Findings on the incidence of tox- $R$ gene in this study are in line with the report of Yang et al. (2017) in which all the tested isolates were also positive for tox-R gene. African salad is at high risk of $V$. parahaemolyticus infections among the foods available in Nigeria sequel to the high pathogenic strains recovered.

The previous study by Letchumanan et al. (2014) attributed Vibrio infections to virulence factors such as the biofilm, tox $R$ gene, $t d h$ and $t r h$. Li et al. (2020) also associated biofilm formation with the tox $R$ gene, a virulence factor ubiquitously present in $V$. parahaemolyticus. Similarly, Ashrafudoulla et al. (2019) stated that $V$. parahaemolyticus biofilm showed a strong genetic relationship with $t d h$ gene. The study of 

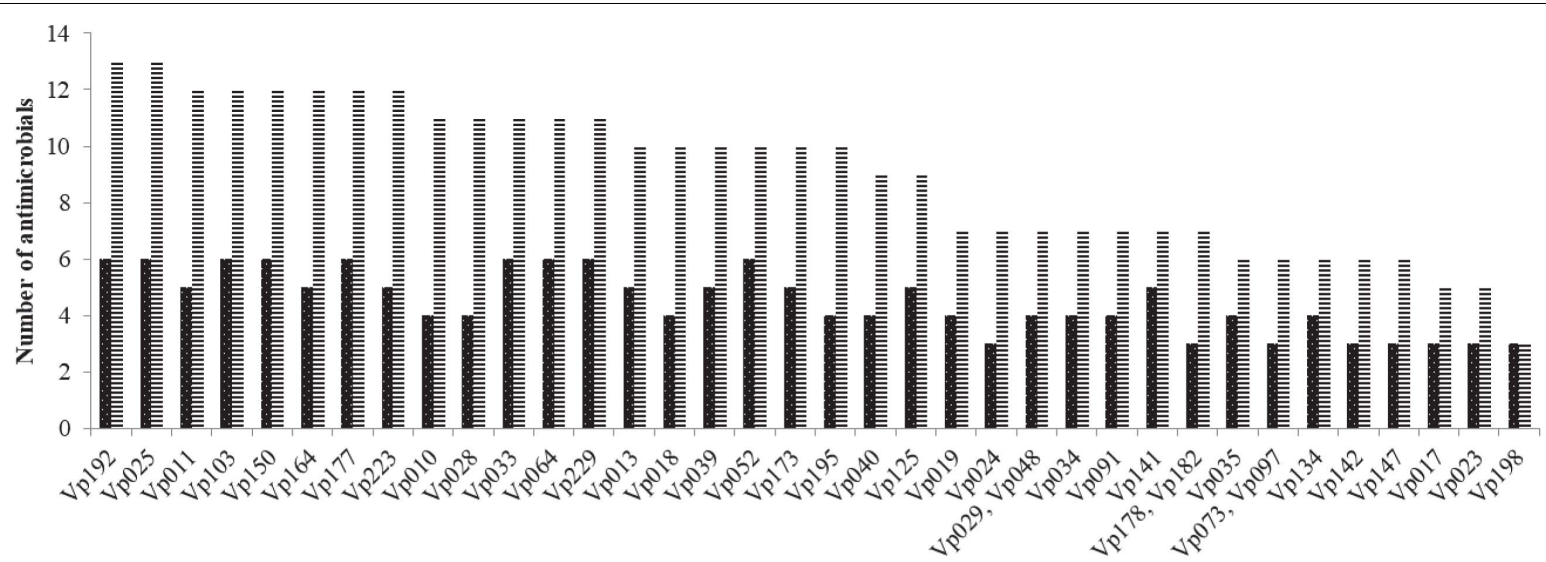

Vibrio parahaemolyticus strains

- Number of antimicrobial class $\equiv$ Number of antibiotics

FIGURE 5 | The MDR profile of $V$. parahaemolyticus from African salads.

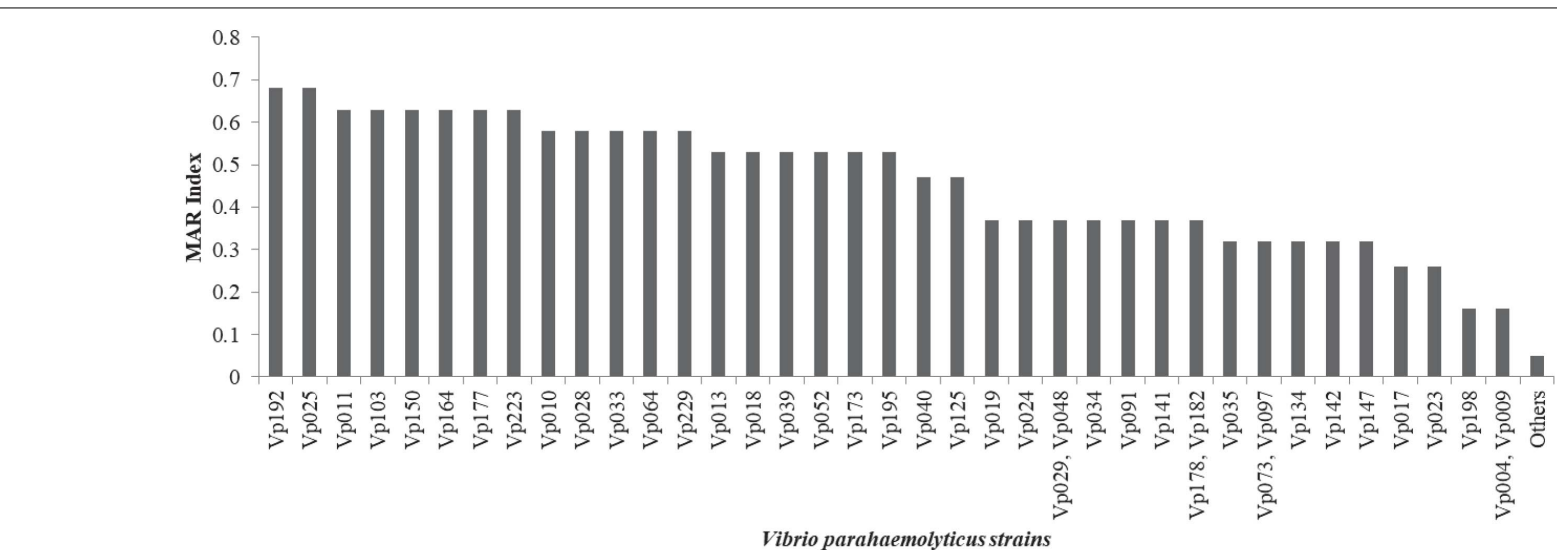

FIGURE 6 | MAR index of $V$. parahaemolyticus recovered from African salads. Others = Vp014, Vp026, Vp038, Vp043, Vp053, Vp056, Vp072, Vp111, Vp149, Vp165, Vp172, Vp175, Vp180, Vp185, Vp194, Vp196, Vp224, and Vp152.

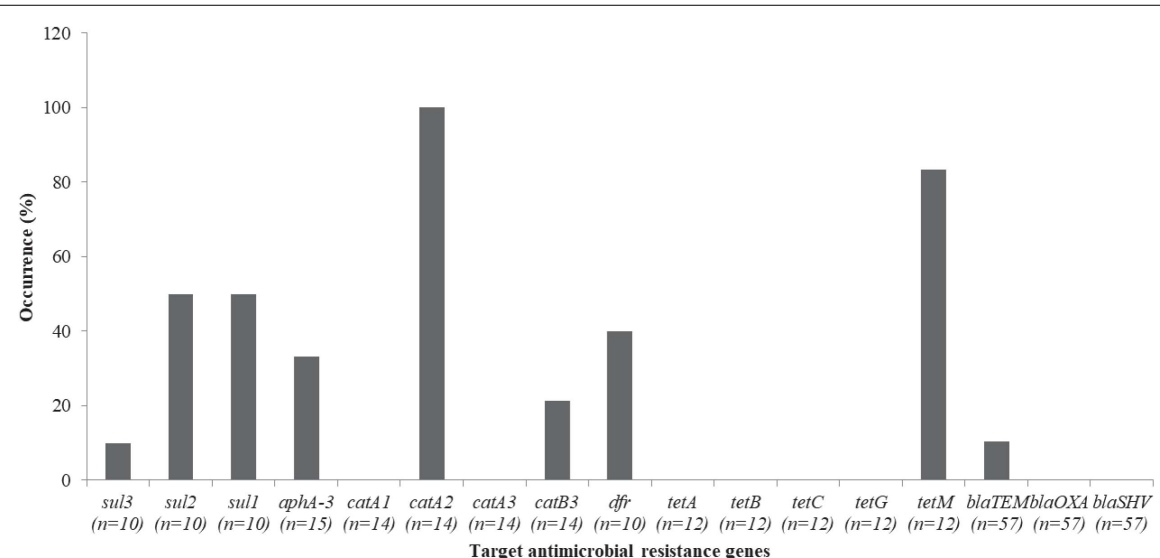

FIGURE 7 | Antibiotic resistance genes in the $V$. parahaemolyticus. 
Ashrafudoulla et al. (2019) stated that biofilm formation by food isolates could result in potential risk to consumer's health. All isolates by Ashrafudoulla et al. (2019) showed strong biofilm formation capacity on food surfaces which was higher compared to our study. Han et al. (2016) reported that both the cultural counts and biofilm formation index values of $V$. parahaemolyticus were stronger at temperatures between $15-37^{\circ} \mathrm{C}$. Han et al. (2016) finalized that exoprotease production, as well as significantly stronger biofilm formation, were produced at $25-37^{\circ} \mathrm{C}$ on food contact surfaces and food.

The $\mathrm{O}$ antigen is a crucial component of bacterial lipopolysaccharide (Samuel et al., 2004). A capsule can be produced by $V$. parahaemolyticus with the variability of the $\mathrm{O}$ antigen vital for bacterial classification depending on external factors. Our result showed that the $\mathrm{O} 2$ serovar was more compared to others detected which tallies to the findings of $\mathrm{Xu}$ et al. (2016); and Li et al. (2020). Also, PCR-detected serotyping of 145 isolates for O-antigen by Xu et al. (2016) revealed that serotypes with the exemption of $\mathrm{O} 6, \mathrm{O} 9$, and $\mathrm{O} 7$, were detected which was not in line with our study as $\mathrm{O} 6$ and $\mathrm{O} 7$ serotypes were detected in our study. Furthermore, our findings disagree with the study of Zhao et al. (2011) that detected the O3 serotype as the most detected serotype from shellfish and the study of Narayanan et al. (2020) that reported the prevalence O1 serotype in $V$. parahaemolyticus recovered from retail food and water samples. Location and serogroups did not correlate the phenotypic and/or genotypic profile of the $V$. parahaemolyticus in our study. Monitoring variation in serogroup could be vital in improving our understanding of food pathogens (such as $V$. parahaemolyticus) responsible for food poisoning. The $\mathrm{O}$ antigen of vibrios as a receptor, domiciled on the bacterial surface can be an important target for specific phages (Xu et al., 2014). This could aid the control and prevention of MDR pathogenic bacteria by phages aiming at specific $\mathrm{O}$ serogroup of $V$. parahaemolyticus.

A significant concern of global health has been a persistent increase in antibiotic-resistant infections. Surveillance of antibiotic-resistant bacteria and dissemination of surveillance findings are crucial in addressing this public health menace (Johnson, 2015). Findings from our study correspond with Xu et al. (2016) that reported high resistance of $V$. parahaemolyticus to ampicillin, cefazolin and cephalothin. Sudha et al. (2014) attributed the resistance of ampicillin and other first-generation antibiotics to their extensive usage in the treatment of $V$. parahaemolyticus thus the increase in resistance and resulting low efficacy. Devi et al. (2009) attributed resistance of $V$. parahaemolyticus to penicillin and other penicillin derivatives to $\beta$-lactamase that are chromosomally encoded. Similarly, Blair et al. (2014) also attributed V. parahaemolyticus resistance to penicillin to likely to be a result of Gram-negative bacteria complexity of their outer membrane which limits antibiotic compounds from entering the outer membrane.

Furthermore, this study levels up with the report of Letchumanan et al. (2015) where the resistance of cefotaxime and ceftazidime (third-generation cephalosporin) to $V$. parahaemolyticus isolates was reported. Similarly, Li et al. (2020) revealed a high resistance of cephalothin; a first-generation cephalosporin. Contrarily, Shaw et al. (2014) reported $V$. parahaemolyticus isolated from the United States to show less resistance to cefotaxime. Also, Hu et al. (2020) denoted that $V$. parahaemolyticus strains were highly sensitive to ceftazidime. Nevertheless, these contradictory reports on the resistance pattern of $V$. parahaemolyticus to 3rd generation cephalosporins could be as a result of a difference in test methodology employed or geographical variability. Furthermore, Beshiru et al. (2020) reported high sensitivity of $V$. parahaemolyticus recovered from ready-to-eat food to cephalothin which is contrary to this study. Shaw et al. (2014) and Tang et al. (2014) documented that the association of $V$. parahaemolyticus with a slight intermediate and resistance to amikacin should be of concern to avoid an elevated level of resistance to aminoglycosides. In this study, a significantly elevated level of amikacin resistance was observed, this occurrence should be of public health concern.

Most V. parahaemolyticus isolated by Lee et al. (2018) were susceptible to nalidixic acid, tetracycline, levofloxacin, gentamicin, imipenem, and sulfamethoxazole/trimethoprim which were in agreement with this study. The previous report by Shaw et al. (2014) demonstrated that all isolates of $V$. parahaemolyticus were fully susceptible to the gentamicin and thus recommended gentamicin as a drug of choice in the treatment for MDR Vibrio infections. The misuse and extensive usage of antibiotics are major factors contributing to the development of ARGs in bacteria and the dissemination of MDR bacterial. The MDR ratio from this study is less than those reported by Daramola et al. (2009) in which $78.9 \%$ of the isolates were multi-resistant. The MDR ratio observed from our study is lesser than those reported by Yang et al. (2017) where strains amounting to $68.38 \%$ were MDR. This is similar to the findings by Ahmed et al. (2018) where all isolates of $V$. parahaemolyticus demonstrated MDR. Generally, evaluating the trend in antimicrobial susceptibility of $V$. parahaemolyticus is of importance as the emergence of multiple drugs microbial resistant infections is a serious clinical problem.

Large proportions of strains of $V$. parahaemolyticus recovered from samples of environmental origin revealed resistance to multiple antibiotics such as ampicillin, carbenicillin, amoxicillin, cefazolin, gentamicin, cephalothin, and ceftazidime (Sudha et al., 2014; Tang et al., 2014; Yano et al., 2014). The MAR index observed in our study is not entirely different from the findings of Tan et al. (2020) in which more than 0.20 MAR indices were reported from $55.83 \%$ of the vibrios. The previous report by Gufe et al. (2019) stated that MAR index $>0.2$ portrays the bacterial strain screened to have originated from sources that are of highrisk where antibiotics are used frequently. The variation in the MAR index of $V$. parahaemolyticus reported in various studies might have been influenced by the differences in resistance patterns which depend on sample sources and geographic distribution (Tunung et al., 2012; Tang et al., 2014). Inappropriate application of antibiotics for bacterial infection prophylactics and widespread of bacteria causing disease is likely an important cause of the emergence and dissemination of MDR in vibrios.

The detection of $d f r$ resistance gene in this study is in line with a previous report by Beshiru et al. (2020) where the detection 
of $d f r 1$ gene which denotes genetic tolerance of trimethoprim resistance was reported. In agreement with $\mathrm{Hu}$ et al. (2020), tet $B$ and blaOXA resistance genes were not detected in this study. Common resistance genes by Jeamsripong et al. (2020) to those of our study were tet(A) (22.1\%) and blaTEM (0.8\%). The upsurge in the ARGs and the dissemination of antimicrobialresistant vibrios could be due to the misuse and overuse of antibiotics (Yano et al., 2014). The significant proportion of antibiotics used currently for therapeutics and the ARGs obtained by pathogens isolated from humans all has an environmental source/origin. Current studies suggest that the functionalities of these determinants in their reservoirs may be distinct from the "weapon-shield" characteristics they carry out. Changes in ecosystems, which include the misuse/abuse of significant proportions of antimicrobials, can alter the population structure and dynamics of microorganisms, including resistance selection, with detrimental effects on human health.

\section{CONCLUSION}

This study confirms that African salads are potential reservoirs for $V$. parahaemolyticus with MAR. The detection of toxigenic and ARGs of $V$. parahaemolyticus gives us comprehensive understanding regarding the occurrence of pathogenic and MDR strains of $V$. parahaemolyticus in African salads. The occurrence of resistance genetic elements of $V$. parahaemolyticus enables the possibility of horizontal dissemination of ARGs among bacteria. The findings from this study are important in defining key monitoring programs, information for risk and exposure assessment of $V$. parahaemolyticus pathogens. Furthermore, important measures which include good hygiene practices by the handlers of food materials, the use of clean preparation

\section{REFERENCES}

Adebayo-Tayo, B. C., Okonko, I. O., John, M. O., Odu, N. N., Nwanze, J. C., and Ezediokpu, M. N. (2011). Occurrence of potentially pathogenic Vibrio species in seafoods obtained from Oron Creek. Adv. Biol. Res. 5, 356-365.

Adedoyin, O. T., Ojuawo, A., Adesiyun, O. O., Mark, F., and Anigilaje, E. A. (2008). Poisoning due to yam flour consumption in five families in Ilorin, central Nigeria. West Afr. Med. J. 27, 41--43.

Adeleke, S. I. (2009). Food poisoning due to yam flour consumption in Kano (Northwest). Nig. Online J. Health Allied Sci. 8:10.

Adio, H. I., Ovuoraini, E. H., and Olubunmi, A. E. (2014). Microbial quality of ready-to-eat barbecue meat (suya) sold on the streets of Lagos State. Int. J. Adv. Pharm. Biol. Chem. 3, 973-982.

Agwa, O. K., Ossai-Chidi, L. N., and Ezeani, C. A. (2014). Microbial evaluation of orange fruit juice sold in Port Harcourt, Nigeria. Am. J. Food Sci. Nutri. Res. 1, 28-33.

Ahmed, H. A., El Bayomi, R. M., Hussein, M. A., Khedr, M. H. E., Abo Remela, E. M., and El-Ashram, A. M. M. (2018). Molecular characterization, antibiotic resistance pattern and biofilm formation of Vibrio parahaemolyticus and V. cholerae isolated from crustaceans and humans. Int. J. Food Microbiol. 274, 31-37. doi: 10.1016/j.ijfoodmicro.2018.03.013

Akintaro, O. A. (2012). Food Handling, hygiene and the role of food regulatory agencies in promoting good health and development in Nigeria. Int. J. Health Med. Inform. 1, 2350-2150.

Arakawa, E., Murase, T., Shimada, T., and Okitsu, T. (1999). Emergence and prevalence of a novel Vibrio parahaemolyticus O3:K6 clone in Japan. Jpn. J. Infect. Dis. 52, 246-247. utensils and proper storage materials could be vital to circumvent cross-contamination.

\section{DATA AVAILABILITY STATEMENT}

The original contributions presented in the study are included in the article/Supplementary Material, further inquiries can be directed to the corresponding author/s.

\section{AUTHOR CONTRIBUTIONS}

$\mathrm{EI}$ and $\mathrm{AB}$ conceived, designed, and performed the experiments. $\mathrm{EI}, \mathrm{AB}, \mathrm{II}, \mathrm{AO}$, and $\mathrm{KU}$ analyzed the data. EI, AB, and II contributed reagents and materials. $\mathrm{EI}, \mathrm{AB}, \mathrm{II}, \mathrm{AO}$, and $\mathrm{KU}$ contributed to the writing of the manuscript. All authors contributed to the article and approved the submitted version.

\section{FUNDING}

This work received support from the African-German Network of Excellence in Science (AGNES), the Federal Ministry of Education and Research (BMBF), and the Alexander von Humboldt Foundation (AvH) from the grant awarded to AB.

\section{SUPPLEMENTARY MATERIAL}

The Supplementary Material for this article can be found online at: https://www.frontiersin.org/articles/10.3389/fmicb. 2021.632266/full\#supplementary-material

Aruwa, C. E., and Ogunlade, S. T. (2016). Classical identification, 16SrDNA sequencing, and molecular characterization of Bacillus species from convenience foods. Bri. J. Appl. Sci. Technol. 15, 1-11. doi: 10.9734/bjast/2016/24803

Ashrafudoulla, M., Mizan, M. F. R., Park, H., Byun, K. H., Lee, N., Park, S. H., et al. (2019). Genetic relationship, virulence factors, drug resistance profile and biofilm formation ability of Vibrio parahaemolyticus isolated from Mussel. Front. Microbiol. 10:513. doi: 10.3389/fmicb.2019.00513

Berutti, T. R., Williams, R. E., Shen, S., Taylor, M. M., and Grimes, D. J. (2014). Prevalence of urease in Vibrio parahaemolyticus from the Mississippi Sound. Lett. Appl. Microbiol. 58, 624-628. doi: 10.1111/la m.12237

Beshiru, A., and Igbinosa, E. O. (2018). Characterization of extracellular virulence properties and biofilm-formation capacity of Vibrio species recovered from ready-to-eat (RTE) shrimps. Microb. Pathog. 119, 93-102. doi: 10.1016/j. micpath.2018.04.015

Beshiru, A., Igbinosa, I. H., and Igbinosa, E. O. (2018). Biofilm formation and potential virulence factors of Salmonella strains isolated from readyto-eat shrimps. PLoS One 13:e0204345. doi: 10.1371/journal.pone.02 04345

Beshiru, A., Igbinosa, I. H., and Igbinosa, E. O. (2021). Characterization of enterotoxigenic Staphylococcus aureus from ready-to-eat seafood (RTES). LWT Food Sci. Technol. 135:110042. doi: 10.1016/j.lwt.2020.110042

Beshiru, A., Okareh, O. T., Okoh, A. I., and Igbinosa, E. O. (2020). Detection of antibiotic resistance and virulence genes of Vibrio strains isolated from readyto-eat shrimps in Delta and Edo States Nigeria. J. Appl. Microbiol. 129, 17-36. doi: $10.1111 /$ jam. 14590 
Blair, J. M. A., Webber, M. A., Baylay, A. J., Ogbolu, D. O., and Piddock, L. J. V. (2014). Molecular mechanisms of antibiotic resistance. Nat. Rev. Microbiol. 13, 42-51.

Bukar, A., Uba, A., and Oyeyi, T. I. (2009). Occurrence of some enteropathogenic bacteria in some minimally and fully processed ready-to-eat foods in Kano metropolis. Nigeria Afr. J. Food Sci. 4, 32-36.

Cal, Y., and Ni, Y. (1996). Purification, characterization, and pathogenicity of urease produced by Vibrio parahaemolyticus. J. Clin. Lab. Anal. 10, 70-73. doi: 10.1002/(sici)1098-2825(1996)10:2<70::aid-jcla2>3.0.co;2-p

Chen, M., Guo, D., Wong, H. C., Zhang, X., Liu, F. X., Chen, H. Y., et al. (2012). Development of O-serogroup specific PCR assay for detection and identification of Vibrio parahaemolyticus. Int. J. Food Microbiol. 159, 122-129. doi: 10.1016/j.ijfoodmicro.2012.08.012

Clinical and Laboratory Standard Institute [CLSI] (2018). A CLSI Supplement for Global Application. Clinical and Laboratory Standards Institute Antimicrobial Susceptibility Testing Standards M02, M07, and M11. M100 Performance Standards for Antimicrobial Susceptibility Testing, 28th Edn. Wayne, PA: Clinical and Laboratory Standard Institute, 296.

Daniel, E. O., Olisaka, F. N., Umunna, O. A., Daodu, A. A., and Odeh, H. O. (2016). Plasmid borne resistance among bacteria isolated from African salads (“Abacha”). J. Adv. Food Sci. Technol. 3, 129-133.

Daramola, B. A., Williams, R., and Dixon, R. A. (2009). In vitro antibiotic susceptibility of Vibrio parahaemolyticus from environmental sources in northern England. Int. J. Antimicrob. Agents 34, 499-500. doi: 10.1016/j. ijantimicag.2009.06.015

Devi, R., Surendran, P. K., and Chakraborty, K. (2009). Antibiotic resistance and plasmid profiling of Vibrio parahaemolyticus isolated from shrimp farms along the coast of India. World J. Microbiol. Biotechnol. 25, 2005-2012. doi: 10.1007/ s11274-009-0101-8

Dike, K. S., Ibezim, H. A., Obiukwu, E. C., Chibundu, E., and Ezemagu, C. O. (2017). "Antibiotic resistance and plasmid profile of bacterial pathogens isolated from street vended foods in Owerri, Nigeria," in Proceedings of the Joint Event on 4th World Congress and Expo on Applied Microbiology \& 2nd International Conference on Food Microbiology Madrid.

Donlan, R. M. (2002). Biofilms: microbial life on surfaces. Emerg. Infect. Dis. 8, 881-890. doi: 10.3201/eid0809.020063

Eni, A. O., Oluwawemitan, I. A., and Oranusi, U. S. (2010). Microbial quality of fruits and vegetables sold in Sango Ota, Nigeria. Afri J. Food Sci. 4, 291-296.

Fadahunsi, I. F., and Makinde, D. (2018). Occurrence, antibiotic susceptibility pattern and physiological studies of Pseudomonas species isolated from readyto-eat foods in Ibadan, Oyo State. J. Appl. Life Sci. Int. 18, 1-9. doi: 10.9734/ jalsi/2018/36208

Fatiregun, A. A., Oyebade, O. A., and Oladokun, L. (2010). Investigation of an outbreak of food poisoning in a resource-limited setting. Trop. J. Health Sci. 17, 1117-4153.

Gufe, C., Hodobo, T. C., Mbonjani, B., Majonga, O., Marumure, J., Musari, S., et al. (2019). Antimicrobial profiling of bacteria isolated from fish sold at informal market in Mufakose. Zimbabwe. Int. J. Food Microbiol. 2019, 1-7. doi: 10.1155/2019/8759636

Gutierrez-West, C. K., Klein, S. L., and Lovell, C. R. (2013). High frequency of virulence factor genes $t d h, t r h$, and th in Vibrio parahaemolyticus strains isolated from a pristine estuary. Appl. Environ. Microbiol. 79, 2247-2252.

Haileselassie, M., Taddele, H., Adhana, K., and Kalayou, S. (2013). Food safety knowledge and practices of abattoir and butchery shops and the microbial profile of meat in Mekelle City. Asian Pac. J. Trop. Biomed. 3, 407-412. doi: 10.1016/s2221-1691(13)60085-4

Haley, B. J., Kokashvili, T., Tskshvediani, A., Janelidze, N., Mitaishvili, N., and Grim, C. J. (2014). Molecular diversity and predictability of Vibrio parahaemolyticus along the Georgian coastal zone of the Black Sea. Front. Microbiol. 5:45. doi: 10.3389/fmicb.2014.00045

Han, N., Mizan, F. R., Jahid, K. I., and Ha, S. (2016). Biofilm formation by Vibrio parahaemolyticus on food and food contact surfaces increases with rise in temperature. Food Cont. 70, 161-166. doi: 10.1016/j.foodcont.201 6.05.054

Hu, Y., Li, F., Zheng, Y., Jiao, X., and Guo, L. (2020). Isolation, molecular characterization and antibiotic susceptibility pattern of Vibrio parahaemolyticus from aquatic products in the southern Fujian Coast, China. J. Microbiol. Biotechnol. 30, 856-867. doi: 10.4014/jmb.2001.01005
Igbinosa, E. O., and Beshiru, A. (2019). Antimicrobial resistance, virulence determinants, and biofilm formation of Enterococcus species from ready-to-eat seafood. Front Microbiol. 10:728. doi: 10.3389/fmicb.2019.00728

Igbinosa, I. H., Beshiru, A., Egharevba, N. E., and Igbinosa, E. O. (2020). Distribution of enterobacteria in ready-to-eat food in cafeterias and retail food outlets in Benin City: public health implications. J. Comm. Med. Pri. Hlth Care 32, 80-94. doi: 10.4314/jcmphc.v32i2.7

Jeamsripong, S., Khant, W., and Chuanchuen, R. (2020). Distribution of phenotypic and genotypic antimicrobial resistance and virulence genes in Vibrio parahaemolyticus isolated from cultivated oysters and estuarine water. FEMS Microbiol. Ecol. 96:fiaa081.

Johnson, A. P. (2015). Surveillance of antibiotic resistance. Phil. Trans. R. Soc. B 370:20140080.

Kim, M., Kwon, T. H., Jung, S. M., Cho, S. H., Jin, S. Y., and Park, N. H. (2013). Antibiotic resistance of bacteria isolated from the internal organs of edible snow crabs. PLoS One 8:e70887. doi: 10.1371/journal.pone.0070887

Kriem, M. R., Banni, B., El Bouchtaoui, H., Hamama, A., El Marrakchi, A., Chaouqy, N., et al. (2015). Prevalence of Vibrio spp. in raw shrimps (Parapenaeus longirostris) and performance of a chromogenic medium for the isolation of Vibrio strains. Lett. Appl. Microbiol. 61, 224-230. doi: 10.1111/lam. 12455

Law, J. W. F., Mutalib, N. S., Chan, K. G., and Lee, L. H. (2015). Rapid methods for the detection of foodborne bacterial pathogens: principles, applications, advantages and limitations. Front. Microbiol. 5:770. doi: 10.3389/fmicb.2014. 00770

Lee, L. H., Ab Mutalib, N. S., Law, J. W. F., Wong, S. H., and Letchumanan, V. (2018). Discovery on antibiotic resistance patterns of Vibrio parahaemolyticus in Selangor reveals carbapenemase producing Vibrio parahaemolyticus in marine and freshwater fish. Front. Microbiol. 9:2513. doi: 10.3389/fmicb.2018. 02513

Letchumanan, V., Chan, K., and Lee, L. (2014). Vibrio parahaemolyticus: a review on the pathogenesis, prevalence and advance molecular identification techniques. Front. Microbiol. 5:705. doi: 10.3389/fmicb.2014.00705

Letchumanan, V., Yin, W. F., Lee, L. H., and Chan, K. G. (2015). Occurrence and antibiotic resistance of Vibrio parahaemolyticus from shellfish in Selangor, Malaysia. Front. Microbiol. 6:1417. doi: 10.3389/fmicb.2015.01417

Li, Y., Xie, T., Pang, R., Wu, Q., Zhang, J., Lei, T., et al. (2020). Food-Borne Vibrio parahaemolyticus in China: prevalence, antibiotic susceptibility, and genetic characterization. Front. Microbiol. 11:1670. doi: 10.3389/fmicb.2020.01670

Lopatek, M., Wieczorek, K., and Osek, J. (2018). Antimicrobial resistance, virulence factors, and genetic profiles of Vibrio parahaemolyticus from seafood. Appl. Environ. Microbiol. 84:e00537-18.

Madueke, S. N., Awe, S., and Jonah, A. I. (2014). Microbiological analysis of street foods along Lokoja-Abuja Express Way, Lokoja. Am. J. Res. Comm. 2, 196-211.

Maky, P. (2013). Nigerian Salad Recipes- How to Make Your Own. Available online at: http://ezinearticles.com/?NigerianSalad-Recipes-How-to-MakeYourOwn\&id=5319370 (accessed on 22 February 2013)

Malcolm, T. T. H., Cheah, Y. K., Radzi, C. W. J. W. M., Kasim, F. A., Kantilal, H. K., and John, T. Y. H. (2015). Detection and quantification of pathogenic Vibrio parahaemolyticus in shellfish by using multiplex PCR and loop-mediated isothermal amplification assay. Food Cont. 47, 664-671. doi: 10.1016/j. foodcont.2014.08.010

Manjusha, S., and Sarita, G. B. (2011). Plasmid associated antibiotic resistance in Vibrio isolated from coastal waters of Kerala. Int. Food Res. J. 18, 1171-1181.

Mizan, M. F. R., Jahid, I. K., and Ha, S. D. (2015). Microbial biofilms in seafood: a foodhygiene challenge. Food Microbiol. 49, 41-55. doi: 10.1016/j.fm.201 5.01 .009

Narayanan, S. V., Joseph, T. C., Peeralil, S., Mothadaka, M. P., and Lalitha, K. V. (2020). Prevalence, virulence characterization, AMR pattern and genetic relatedness of Vibrio parahaemolyticus isolates from retail seafood of Kerala, India. Front. Microbiol. 11, 592. doi: 10.3389/fmicb.2020.00592

Obaidat, M. M., Salman, A. E. B., and Roess, A. A. (2017). Virulence and antibiotic resistance of Vibrio parahaemolyticus isolates from seafood from three developing countries and of worldwide environmental, seafood, and clinical isolates from 2000 to 2017. J. Food Prot. 80, 2060-2067. doi: 10.4315/ 0362-028x.jfp-17-156

Obande, G., Umeh, E., Azua, E., Chuku, A., and Adikwu, P. (2018). Incidence and antibiotic susceptibility pattern of Escherichia coli and Staphylococcus aureus 
isolated from meat pie sold in a Nigerian North Central town. Janaki Med. Coll. J. Med. Sci. 6, 21-28. doi: 10.3126/jmcjms.v6i1.20571

Oguwike, F. N., Olisah, M. C., Nwadighoha, A. N., Emenuga, V. N., and Ezekwueme, E. N. (2014). Evaluation of pathogenic bacterial contaminants in road side African salad (Manihot esculenta) and their effect in the gastro intestinal system of subjects in Enugu Nigeria. IOSR J. Dent. Med. Sci. 13, 98-103. doi: 10.9790/0853-131998103

Oludare, A. O., Ogundipe, A., Odunjo, A., Komolafe, J., and Olatunji, I. (2016). Knowledge and food handling practices of nurses in a tertiary health care hospital in Nigeria. J. Environ. Health 78, 32-39.

Oramadike, C., and Ogunbanwo, S. T. (2015). Prevalence and antimicrobial susceptibility of Vibrio parahaemolyticus isolated from seafoods in Lagos Lagoon Nigeria. Cogent Food Agr. 1:1041349. doi: 10.1080/23311932.2015. 1041349

Oranusi, S., Braide, W., and Etinosa-Okankan, O. J. (2013a). Prevalence of geohelminthes on selected fruits and vegetables sold in Owerri, Imo State, Nigeria. Afr. J. Food Sci. Tech. 4, 35-43.

Oranusi, S., Braide, W., Eze, U. C., and Chinakwe, E. (2013b). Quality aspects of African salad. J. Emerg. Trends Eng. Appl. Sci. 4, 287-292.

Osagbemi, G., Abdullahi, A., and Aderibigbe, S. (2010). Knowledge, attitude and practice concerning food poisoning among residents of Okene Metropolis. Nigeria Res. J. Soc. Sci. 1, 61-64.

Osawa, R., Okitsu, T., Morozumi, H., and Yamai, S. (1996). Occurrence of ureasepositive Vibrio parahaemolyticus in Kanagawa, Japan, with specific reference to presence of thermostable direct hemolysin (TDH) and the TDH-related hemolysin genes. Appl. Environ. Microbiol. 62, 725-727. doi: 10.1128/aem.62. 2.725-727.1996

Quadri, F., Chowdhury, N. R., Takeda, Y., and Nair, G. B. (2005). "Vibrio parahaemolyticus- seafood safety and associations with higher organisms," in Oceans and Health: Pathogens in the Marine Environment, eds S. Belkin and R. R. Colwell (New York, NY: Springer), 277-295. doi: 10.1007/0-387-237097_11

Rahimi, E., Ameri, M., Doosti, A., and Gholampour, A. R. (2010). Occurrence of toxigenic Vibrio parahaemolyticus strains in shrimp in Iran. Foodborne Pathog. Dis. 7, 1107-1111.

Raszl, S. M., Froelich, B. A., Vieira, C. R., Blackwood, A. D., and Noble, R. T. (2016). Vibrio parahaemolyticus and Vibrio vulnificus in South America: water, seafood and human infections. J. Appl. Microbiol. 121, 1201-1222.

Samuel, G., Hogbin, J. P., Wang, L., and Reeves, P. R. (2004). Relationships of the Escherichia coli O157, O111, and O55 O-antigen gene clusters with those of Salmonella enterica and Citrobacter freundii, which express identical O antigens. J. Bacteriol. 186, 6536-6543. doi: 10.1128/jb.186.19.6536-6543.2004

Shaw, K. S., Goldstein, R. E., He, X., Jacobs, J. M., Crump, B. C., and Sapkota, A. R. (2014). Antimicrobial susceptibility of Vibrio vulnificus and Vibrio parahaemolyticus recovered from recreational and commercial areas of Cheaspeake Bay and Maryland coastal bay. PLoS One 9:89616. doi: 10.1371/ journal.pone.0089616

Smith, I. S., Agomo, C. O., Bamidele, M., Opere, O. B., and Aboaba, O. O. (2010). Survey of food handlers in bukas (a type of local restaurant) in Lagos, Nigeria about typhoid fever. Sci. Res. 2, 951-956. doi: 10.4236/health.2010.28141

Sudha, S., Mridula, C., Silvester, R., and Hatha, A. A. (2014). Prevalence and antibiotic resistance of pathogenic vibrios in shellfishes from Cochin market. Indian J. Geo. Mar. Sci. 43, 815-824.

Sujeewa, A. K. W., Norrakiah, A. S., and Laina, M. (2009). Prevalence of toxic genes of Vibrio parahaemolyticus in shrimps (Penaeus monodon) and culture environment. Int. Food Res. J. 16, 89-95.

Tan, C. W., Malcolm, T. T. H., Kuan, C. H., Thung, T. Y., Chang, W. S., Loo, Y. Y., et al. (2017). Prevalence and antimicrobial susceptibility of Vibrio parahaemolyticus isolated from short Mackerels (Rastrelliger brachysoma) in Malaysia. Front. Microbiol. 8:1087. doi: 10.3389/fmicb.2017.01087

Tan, C. W., Rukayadi, Y., Hasan, H., Thung, T. Y., Lee, E., Rollon, W. D., et al. (2020). Prevalence and antibiotic resistance patterns of Vibrio parahaemolyticus isolated from different types of seafood in Selangor, Malaysia. Saudi J. Biol. Sci. 27, 1602-1608. doi: 10.1016/j.sjbs.2020.01.002
Tang, J. Y. H., Wan-Rosli, W. F., Abdul-Razak, N. H., Yeo, C. C., Abu Bakar, C. A., and Son, R. (2014). Incidence and antibiogram of Vibrio parahaemolyticus in processed and frozen bivalve mollusks in Kuala Terengganu, Malaysia. Int. Food Res. J. 21, 1349-1353.

Tunung, R., Jeyaletchumi, P., Noorlis, A., Tang, Y. H., Sandra, A., and Ghazali, F. M. (2012). Biosafety of Vibrio parahaemolyticus from vegetables based on antimicrobial sensitivity and RAPD profiling. Int. Food Res. J. 19, 467-474.

Tunung, R. I., Margaret, S. P., Jeyaletchumi, P., Chai, L. C., Tuan Zainazor, T. C., Ghazali, F. M., et al. (2010). Prevalence and quantification of Vibrio parahaemolyticus in raw salad vegetables at retail level. J. Microbiol. Biotechnol. 20, 391-396. doi: 10.4014/jmb.0908.08009

Uzeh, R. E., Alade, F. A., and Bankole, M. (2009). The microbial quality of prepacked mixed vegetable salad in some retail outlets in Lagos, Nigeria. Afr. J. Food Sci. 3, 270-272.

Velazquez-Roman, J., Leon-Sicairos, N., Flores-Villasenor, H., Villafana- Rauda, S., and Canizalez-Roman, A. (2012). Association of pandemic Vibrio parahaemolyticus O3:K6 present in the coastal environment of Northwest Mexico with cases of recurrent diarrhea between 2004 and 2010. Appl. Environ. Microbiol. 78, 1794-1803. doi: 10.1128/aem.06953-11

Vincent, M., Chan, C. S. W., and Apun, K. (2015). Molecular confirmation and characterization of Vibrio parahaemolyticus from retailed fish. Inter. Food Res. J. 22, 1705-1710.

Wang, R., Zhong, Y., Gu, X., Yuan, J., Saeed, A. F., and Wang, S. (2015). The pathogenesis, detection, and prevention of Vibrio parahaemolyticus. Front. Microbiol. 6:144. doi: 10.3389/fmicb.2015.00144

World Health Organization [WHO] (2009). Global Burden of Disease. Geneva: WHO.

Wu, Y., Wen, J., Ma, Y., Ma, X., and Chen, Y. (2014). Epidemiology of foodborne disease outbreaks caused by Vibrio parahaemolyticus, China, 2003-2008. Food Cont. 46, 197-202. doi: 10.1016/j.foodcont.2014.05.023

$\mathrm{Xu}$, X., Cheng, J., Wu, Q., Zhang, J., and Xie, T. (2016). Prevalence, characterization, and antibiotic susceptibility of Vibrio parahaemolyticus isolated from retail aquatic products in North China. BMC Microbiol. 16:32. doi: 10.1186/s12866-016-0650-6

Xu, X., Wu, Q., Zhang, J., Cheng, J., Zhang, S., and Wu, K. (2014). Prevalence, pathogenicity and serotypes of Vibrio parahaemolyticus in shrimp from Chinese retail markets. Food Cont. 46, 81-85. doi: 10.1016/j.foodcont.2014. 04.042

Yang, Y., Xie, J., Li, H., Tan, S., Chen, Y., and Yu, H. (2017). Prevalence, antibiotic susceptibility and diversity of Vibrio parahaemolyticus isolates in seafood from South China. Front. Microbiol. 8:2566. doi: 10.3389/fmicb.2 017.02566

Yano, Y., Hamano, K., Satomi, M., Tsutsui, I., and Aue-umneoy, D. (2014). Diversity and characterization of oxytetracycline-resistant bacteria associated with non-native species, white-leg shrimp (Litopenaeus vannamei), and native species, black tiger shrimp (Penaeus monodon), intensively cultured in Thailand. J. Appl. Microbiol. 110, 713-722. doi: 10.1111/j.1365-2672.2010. 04926.x

Zhao, F., Zhou, D., Cao, H. H., Ma, L. P., and Jiang, Y. H. (2011). Distribution, serological and molecular characterization of Vibrio parahaemolyticus from shell fish in the eastern coast of China. Food Cont. 22, 1095-1100. doi: 10.1016/ j.foodcont.2010.12.017

Conflict of Interest: The authors declare that the research was conducted in the absence of any commercial or financial relationships that could be construed as a potential conflict of interest.

Copyright (C) 2021 Igbinosa, Beshiru, Igbinosa, Ogofure and Uwhuba. This is an open-access article distributed under the terms of the Creative Commons Attribution License (CC BY). The use, distribution or reproduction in other forums is permitted, provided the original author(s) and the copyright owner(s) are credited and that the original publication in this journal is cited, in accordance with accepted academic practice. No use, distribution or reproduction is permitted which does not comply with these terms. 